\title{
Role of conserved hydrophobic amino acids in androgen receptor AF-1 function
}

\author{
R Betney and I J McEwan \\ Department of Molecular and Cell Biology, Institute of Medical Sciences, University of Aberdeen, Foresterhill, Aberdeen AB25 2ZD, UK \\ (Requests for offprints should be addressed to I J McEwan; Email: iain.mcewan@abdn.ac.uk)
}

\begin{abstract}
The intracellular androgen receptor (AR) is a ligand-activated transcription factor. Upon binding the steroids testosterone or dihydrotestosterone, the activated receptor translocates to the nucleus, binds to specific DNA response elements and interacts with the transcription machinery in order to regulate gene transcription. In the present study, we have described a highly conserved region (amino acids 224-258) within the AR AF-1 domain and have investigated the role of conserved bulky hydrophobic residues in gene regulation. Mutating pairs of residues (I229A/L236A; V240A/V242A; L251A/L254A) reduced transactivation activity by $25-40 \%$. Mutating residues M244, L246 and V248 to alanines had a more dramatic affect on receptor activity, disrupting activity by at least $60 \%$. The latter mutations also disrupted binding to the RNA polymerase-associated protein 74 subunit of the general transcription factor TFIIF. The protein conformation and stability of the mutant polypeptide in vitro was not significantly different from the wild type. None of the mutations tested disrupted binding of the AF-1 domain with the coactivator protein steroid receptor coactivator-1a. Thus we have concluded that conserved hydrophobic residues are important for receptor-dependent gene transcription and that M244, L246 and V248 are part of the binding interface for TFIIF.
\end{abstract}

Journal of Molecular Endocrinology (2003) 31, 427-439

\section{Introduction}

The steroids testosterone and dihydrotestosterone regulate patterns of gene expression through binding to and activation of the intracellular androgen receptor (AR) (for review see Gelman 2002). The AR protein is organised into discrete structural and functional domains: the C-terminalligand binding domain (LBD) and the central DNA-binding domain (DBD) show significant homology between ARs of different species and with other members of the nuclear receptor superfamily. In contrast, the N-terminus of the protein is more divergent and is characterised by homo-polymer tracts of glutamine, glycine and proline residues. Regions within the $\mathrm{N}$-terminus of the human and rat receptors important for transactivation have been delineated by deletion analysis, the use of fusion proteins and point mutations (Jenster et al. 1991, 1995, Simental et al. 1991, Chamberlain et al. 1996). These studies have highlighted a relatively large region between amino acids 142 and 485 as being important for transactivation; this is termed $\mathrm{AF}-1$ and retains at least $70 \%$ of the activity of the full-length AR-N-terminal domain (NTD) (Jenster et al. 1995, Reid et al. 2002b). The AF-1 function of the AR has a clear modular structure and can be subdivided into transcription activation unit (TAU)-1 (amino acids 100-370) and TAU-5 (amino acids 360-528) (Jenster et al. 1995). Recently, our group has shown that the AF-1 domain is structurally flexible and adopts a more stable structure and proteaseresistant conformation in the presence of a target protein, the general transcription factor TFIIF, or structure-stabilising solutes (Reid et al. 2002a).

The mechanism(s) of AR-dependent transactivation is certain to involve both direct and indirect interactions with the transcriptional machinery. Interactions involving the $\mathrm{AF}-1$ domain and a number of protein targets have been described. From mapping studies, it appears that TFIIF (McEwan \& Gustafsson 1997, Reid et al. 2002b), a novel coactivator ART-27 (Markus et al. 2002) and 
the co-repressor silencing mediator of retinoic acid and thyroid hormone receptors (Dotzlaw et al. 2002) bind predominantly to sequences within the TAU-1 region, while the binding sites for p160 steroid receptor coactivators (Bevan et al. 1999, Ma et al. 1999, Callewaert et al. 2003), and the transcription factors SMAD3 (Hayes et al. 2001, Kang et al. 2001) and signal transducer and activator of transcription-3 (Ueda et al. 2002) co-localise to the TAU-5 region. A recently described novel RING domain (a zinc-binding motif) protein with ubiquitin-ligase activity, termed AR N-terminal domain interacting protein (ARNIP), binds to sequences immediately N-terminal of the AF-1 domain and that overlap with TAU-1 (Beitel et al. 2002). Interestingly, expansion of the largest poly-glutamine repeat (located at amino acid 58), which is associated with the neuromuscular disorder Kennedy's disease, reduced binding of ARNIP (Beitel et al. 2002). To date, one of the best characterised interactions involving the AR-NTD is with the AR-LBD: the main determinants that mediate this intramolecular interaction lie outwith AF-1 and have been mapped to an FxxLF motif (amino acids 23-27) (see He \& Wilson 2002 for recent review, Callewaert et al. 2003).

Transactivation domains have previously been characterised on the basis of the prevalence of certain types of amino acids: this gave rise to so-called acidic, glutamine-rich, proline-rich and isoleucine-rich activators. A common feature shared by transactivation domains is a general lack of stable structure but having the ability to adopt a more structured conformation, possibly involving a coil to helix transition, in a more hydrophobic environment (Donaldson \& Capone 1992, O'Hare \& Williams 1992, Schmitz et al. 1994, Dahlman-Wright et al. 1995, McEwan et al. 1996, Shen et al. 1996a, Hua et al. 1998, Baskakov et al. 1999, Hi et al. 1999, Lee et al. 2000, Reid et al. 2002a) or upon specific protein-protein interactions (McEwan et al. 1996, Shen et al. 1996b, Radhakrishnan et al. 1997, Uesugi et al. 1997, Wärnmark et al. 2001, Freedman et al. 2002, Reid et al. 2002a, Dames et al. 2003). The ARtransactivation domain has a relatively high proportion of acidic residues (10\%), alanines (13\%), leucines $(10 \%)$, serine $(12 \%)$ and glycine $(17 \%) ; 16$ of the glycines form a single repeat. Although transactivation domains lack significant if any primary sequence identity, mutational analysis of both viral and cellular activators has revealed the importance of hydrophobic amino acids (Hope et al. 1988, Cress \& Trizenberg 1991, Regier et al. 1993, Walker et al. 1993, Blair et al. 1994, Lin et al. 1994, Metz et al. 1994, Xing \& Quinn 1994, Drysdale et al. 1995, Folkers et al. 1995, Jackson et al. 1996, Almlölf et al. 1997, Green et al. 1998, Callus \& Mathey-Prevot 2000, Tung et al. 2001). Thus mutational analysis of the viral activator VP16 highlighted the importance of a critical phenylalanine residue (position 442) and flanking acidic residues for transactivation activity (Cress \& Trizenberg 1991, Regier et al. 1993, Walker et al. 1993). Similarly, hydrophobic amino acids and adjacent acidic residues are important for transactivation by the retinoic acid $\beta 2$ receptor (RAR ß2) (Folkers et al. 1995). While clusters of hydrophobic amino acids within two helical regions of the glucocorticoid receptor (GR) $\tau$ l core domain were found to be critical for activity, acidity of this domain per se was of less importance (Almlölf et al. 1995, 1997).

In order to better understand the mechanism of transactivation by the AR we have analysed a number of highly conserved hydrophobic residues within the AF-1 domain. Groups of hydrophobic amino acids were mutated to alanines and the effects on reporter gene activity, protein conformation and protein-protein interactions determined. These studies suggested that conserved hydrophobic residues play a role in receptordependent transactivation and delineate a binding surface for the general transcription factor TFIIF.

\section{Materials and methods}

\section{Plasmid constructs and site-directed mutagenesis}

Mutations (M) were created within the AR4 polypeptide, amino acids 142-485: M1 to M4 were created by site-directed mutagenesis using the oligonucleotide primers described in Table 1 . Mutations were created using the QuikChange kit (Stratagene, La Jolla, CA, USA): the template plasmids used were pET-AR4 (McEwan \& Gustafsson 1997) for M1, M2 and M4 and pRS-AR4-Lex (Reid et al. 2002b) for M3. The authenticity of all plasmids was confirmed by restriction enzyme digest and DNA sequencing of the insert. 
Table 1 Site-directed mutagenesis primers. Mutated codons are highlighted in bold and introduced restiction enzyme sites are underlined

\section{Oligonucleotides}

AR4 mutant
M1

I229A/L236A

M2

V240A/V242A

M3

M244A/L246A

V248A

M4

L251A/L254A
Sense

Antisense

Sense Antisense

Sense Antisense

Sense Antisense
5'-CGACCGC T T C T GA C A A CGCCA A G A A G C T T G T A A G-3' 5'-C T TACAAGCT TCC T T GGCGTTGTCA A A G CGGTCG-3' Hindlll
5'-G T A A G G C A G C G T C GG C T A G C A T GGG C C - $3^{\prime}$ $5^{\prime}-G G C C C A T G C T A G C C G A C G C T G C C T T A C-3^{\prime}$ Nhel

5'-C G T T T C C G C G G G C G C G G T G C G A A G G C T T G-3'

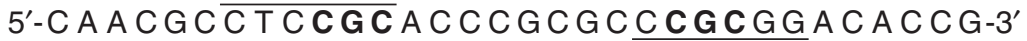
Sacll

5'-G T G G A G G C G G C G G A G C A T G C T A G C C C A G G G G-3' 5'-C C C C T GGGCTAGCA T GC T C CGCCGC C T C C A C- $3^{\prime}$ Nhel

Mutant cDNAs M1, M2 and M4 were subsequently subcloned into pRS315-Lex (Almlölf et al. 1997), while M3 was subcloned into pET-19bm. DNA inserts were amplified using the proof-reading enzyme systems Expand (Boehringer Mannheim, Mannheim, Germany) or Pwo (Hybaid, Ashford, Middlesex, UK); all inserts were confirmed by DNA sequencing.

\section{Yeast reporter gene assay}

The yeast Saccharomyces cerevisiae strain W303-1A (MAT $\alpha$, ade2-1, ura3-1, his3-11, trp1-1, leu2-3, leu2-112, can1-100, gal $^{+}$; American Type Culture Collection, Manassas, VA, USA) was transformed with the reporter plasmid pLGZ-2 LexA (Wright et al. 1990, Almlölf et al. 1997) and pRS315-LexA, pRS-AR4-LexA or pRS-AR4 M1-4-LexA using the lithium acetate method (Gietz \& Woods 1994). Transformants were selected on synthetic defined (SD)-leucine, -uracil agar plates. Colonies were then selected and inoculated into $20 \mathrm{ml}$ SD medium containing $2 \%$ galactose to induce expression of recombinant proteins and grown at $30^{\circ} \mathrm{C}$. After $24 \mathrm{~h}$, cells were harvested by centrifugation and lysed using glass beads and mechanical shaking in

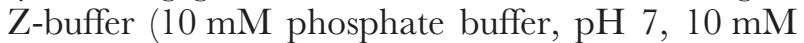
$\mathrm{KGl}$ and $\left.1 \mathrm{mM} \quad \mathrm{MgSO}_{4} 7 \mathrm{H}_{2} \mathrm{O}\right)$, supplemented with $1 \mathrm{mM}$ phenylmethylsulphonyl fluoride (PMSF) and $1 \mathrm{mM}$ dithiothreitol (DTT). The soluble protein fraction was then recovered by centrifugation and protein concentration determined by the method of Bradford (BioRad, Hercules, CA, USA). $\beta$-Galactosidase activity was measured using the substrate o-nitrophenol $\beta$-D-galacto-pyranoside (ONPG) as previously described (Wright et al. 1990, Almlölf et al. 1997). The absorbance at $405 \mathrm{~nm}$ was measured at time 0 , 20 and $40 \mathrm{~min}$ using a microplate reader (Molecular Devices, Sunnyvale, CA, USA) and $\beta$-galactosidase activity expressed as nM ONPG converted $/ \mathrm{min}$ per $\mathrm{mg}$ protein: specific activity $=$ reaction volume $(\mathrm{ml}) \times \Delta \mathrm{A}_{405 \mathrm{~nm}} / 0 \cdot 0016 \times$ extract volume $(\mathrm{ml}) \times$ time $(\mathrm{min}) \times$ [protein] $(\mathrm{mg} / \mathrm{ml})$.

\section{Expression and purification of recombinant proteins}

AR4 and AR4 M1 to M4 polypeptides were expressed in Escherichia coli strain BLR (DE3) by inducing with $1 \mathrm{mM}$ isopropyl $\beta$-D-thiogalactoside and purified from the soluble fraction by $\mathrm{Ni}^{2+}$ nitriloacetate-agarose affinity chromatography. The purified AR proteins were dialysed against $25 \mathrm{mM}$ HEPES (pH 7.9), $100 \mathrm{mM}$ sodium acetate, 5\% glycerol and $1 \mathrm{mM}$ DTT. Protein 
concentrations were estimated against bovine serum albumin (BSA) standards using Bradford reagent (BioRad).

\section{Microtitre plate-based protein-protein interaction assay}

RNA polymerase-associated protein (RAP)74, the large subunit of TFIIF, and steroid receptor coactivator (SRC)-1a polypeptides were synthesised in vitro using a coupled-rabbit reticulocyte lysate system (Promega, Madison, WI, USA). Purified recombinant AR4 and mutant proteins in binding buffer (20 mM HEPES, pH 7·9, 10\% glycerol, $100 \mathrm{mM} \mathrm{KCl}, 0.2 \mathrm{mM}$ EDTA, $5 \mathrm{mM} \mathrm{MgCl}_{2}$, $5 \mathrm{mM} \quad \beta$-mercaptoethanol and $0.2 \mathrm{mM}$ PMSF) were allowed to adsorb to the surface of a scinti-microtitre plate (Perkin Elmer Life Sciences, Pangbourne, Berkshire, UK) at a concentration of $200 \mathrm{nM}$ per well. Control wells were incubated with $200 \mathrm{nM}$ BSA in the same buffer. The solutions were subsequently removed and the wells blocked overnight with binding buffer plus $5 \mathrm{mg} / \mathrm{ml}$ BSA before incubating with binding buffer containing $1 \mathrm{mg} / \mathrm{ml} \mathrm{BSA}$ and ${ }^{35} \mathrm{~S}$ radiolabelled RAP74 or SRC-1a polypeptides. After extensive washing with binding buffer plus $1 \mathrm{mg} / \mathrm{ml}$ BSA, the bound radiolabelled proteins were counted directly using a micro- $\beta$-counter. In the competition experiment, after removal of the blocking solution the wells were preincubated with a 2 molar excess of either RAP74-C-terminal domain (CTD) (amino acids 363-517) or glutathione S-transferase (GST) prior to incubating with SRG-CTD (amino acids 977-1441). The wells were washed and the bound radioactivity measured as before. For each labelled protein, binding to AR4 or receptor mutants was measured relative to the BSA-only control and the relative binding was then plotted with $\mathrm{BSA}=1$.

\section{Fluorescence spectroscopy}

Fluorescence measurements were made using a Shimadzu 1501 spectrofluorimeter (Shimadzu Corporation, Kyoto 604, Japan) with excitation and emission band widths of $10 \mathrm{~nm}$, using $1 \mathrm{~cm}$ path length quartz cuvettes. The fluorescence spectra of AR4 $(25 \mu \mathrm{g} / \mathrm{ml}$ in dialysis buffer $)$ were read at an excitation wavelength of 278 and emission wavelengths between 300 and $400 \mathrm{~nm}$. Excitation at $278 \mathrm{~nm}$ results in fluorescence emission from tryptophan and tyrosine residues; in addition there can be energy transfer from tyrosine to tryptophan. All spectra were corrected for the contribution of the buffer and solute concentrations.

\section{Partial proteolysis assay}

Purified, recombinant AR4, AR4-M1 to -M4 were diluted to a final concentration of $50 \mathrm{pM} / 10 \mu \mathrm{l}$ reaction in proteolysis buffer $(25 \mathrm{mM}$ HEPES, $\mathrm{pH}$ $7 \cdot 9,10 \%$ glycerol, $0.2 \mathrm{mM}$ EDTA, $5 \mathrm{mM} \mathrm{MgCl}_{2}$, $20 \mathrm{mM} \mathrm{CaCl}_{2}$ and $60 \mathrm{mM} \mathrm{KCl}$ ) and digested with $0 \cdot 25 \mathrm{ng} / \mu \mathrm{l}$ trypsin for $2,4,6,8$ and $10 \mathrm{~min}$ at room temperature. Reactions were stopped by the addition of $2 \times$ SDS-PAGE sample buffer and heating to $75^{\circ} \mathrm{C}$ for $5 \mathrm{~min}$. The samples were separated on a $12.5 \%$ SDS-PAGE gel, transferred to polyvinylidene difluoride membrane and $\mathrm{N}$-terminal digestion fragments of the protein were visualised by Western blotting using an anti-poly histidine tag antibody and visualised by enhanced chemiluminescence.

\section{Results}

\section{Role of conserved hydrophobic residues in receptor-dependent transactivation}

Analysis of the primary sequence of the AR-NTD from different organisms, from primates through to Xenopus and a number of fish species, has revealed considerable variation in both length and composition. It is striking, therefore, that there are three regions within the AR-NTD that showed varying degrees of conservation: amino acids 1-30, 224-258 and 500-541 (numbering for the human receptor with a glutamine repeat of 20 residues and a glycine repeat of 16). The region between amino acids 224 and 258 is of particular note as it contained $37 \%$ amino acid identity over 35 residues, which rose to $66 \%$ similarity when conservative changes are taken into consideration, and it lay within the so-called AF-1 transactivation function of the receptor (Fig. 1). This region was predicted to form an $\alpha$-helix flanked by $\beta$-strands, followed by a second smaller helix (Fig. 1).

Of particular interest was the conservation of hydrophobic amino acids and negative charge in this region and it would seem likely that amino acid residues conserved during evolution will play an 


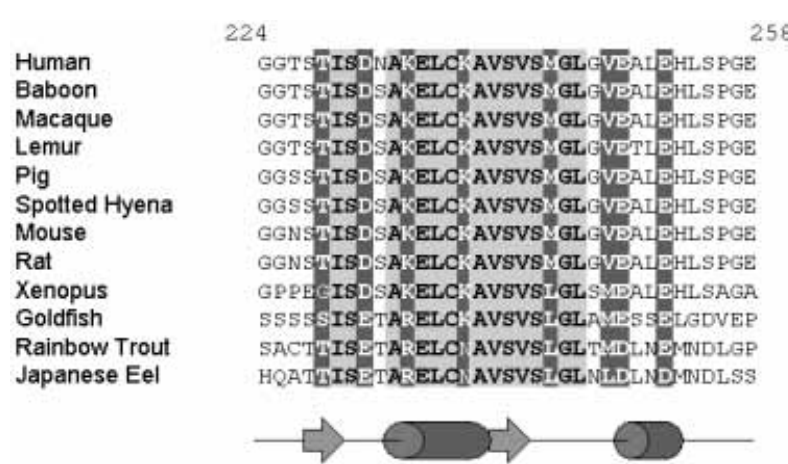

Figure 1 Conserved hydrophobic and charged amino acids within the AR-NTD. Alignment of sequences from amino acid 224 to 258 (numbering for the human AR) and secondary structure predictions (see Combet et al. 2000).

important role in protein structure and/or function. Furthermore, studies on a wide range of transactivation domain polypeptides have provided convincing evidence for the importance of hydrophobic residues for transactivation function (see Introduction). Thus, we targeted the conserved bulky hydrophobic residues in groups of two or three, within this highly conserved region, for mutagenesis (Fig. 2). Mutations were introduced in the context of an AR4 (amino acids 142-485) fusion protein with the LexA DBD (amino acids 1-87) and the ability to activate a reporter gene in the yeast Saccharomyces cerevisiae was measured. The yeast reporter gene assay has a number of advantages including the absence of nuclear receptors, inducible expression levels and the

\section{Transactivation DNA Steroid Binding Binding Dimerisation}

Transactivation?

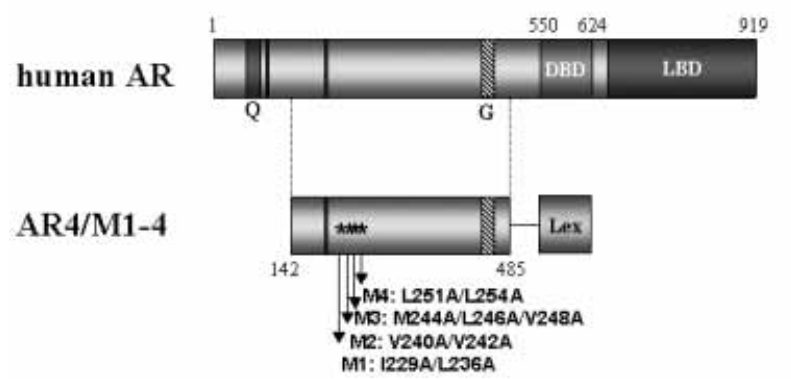

Figure 2 Schematic representation of the human AR. The Figure shows the domain structure and the glutamine $(Q)$ and glycine $(G)$ repeats. The location of the mutations M1 to M4 within the AR-transactivation domain are indicated.
A.

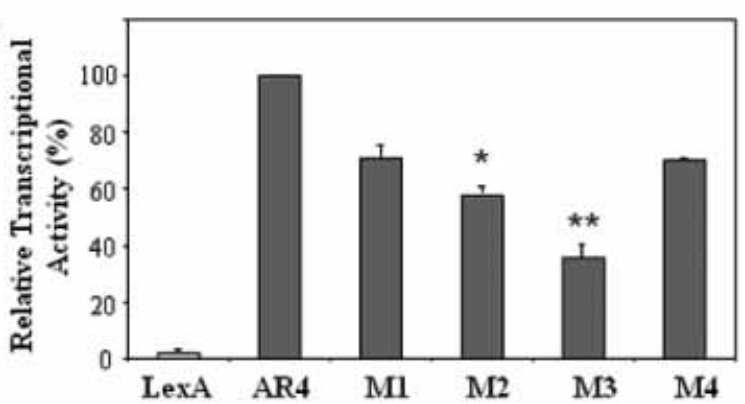

B.

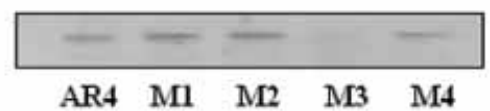

Figure 3 Yeast reporter gene assay. (A) $\beta$-Galactosidase activity was measured in triplicate after expression of the wild-type or mutant AR4-Lex fusion proteins. The figure shows representative data from two independent experiments with the mean \pm S.D. relative activity of triplicate measurements. Expression of LexA alone was used as a background control and wild-type AR4 activity was set to $100 \%$. The observed decrease in activity for AR4-M2 and -M3 relative to wild type was statistically significant with $P<0.05\left(^{*}\right)$ and $\left.0.01{ }^{* *}\right)$ respectively, using Student's $t$-test. (B) Western blot analysis of expressed AR-fusion proteins using the N19 anti-lexA antibody (Santa Cruz Biotechnology, Santa Cruz, CA, USA).

presence of expression and reporter plasmids in each cell in culture due to the use of auxotrophic markers. The present studies focused on the isolated $\mathrm{AF}-1$ of the $\mathrm{AR}$ in order to determine the role of specific mutations on the transactivation function. We have previously shown that AR4 robustly activates transcription in yeast cells, retaining $70 \%$ of the activity of the full-length AR-NTD and that this activity is significantly decreased by the introduction of a double-point mutation originally described as impairing the activity of the full-length rat $\mathrm{AR}$ in a mammalian cell culture assay (Reid et al. 2002b). Furthermore, the results obtained in yeast for the isolated $\mathrm{AR}$ $\mathrm{AF}-1$ relative to the AR-NTD were in good agreement with those reported for GAL4 DBD fusion proteins analysed in HeLa cells (Jenster et al. 1995). Thus, yeast cells provide a suitable in vivo model for investigating receptor-dependent transactivation. Figure $3 \mathrm{~A}$ shows that the transactivation activity was compromised for all four mutant polypeptides. AR4-M1, -M2 and -M4 retained about $60-70 \%$ of the activity of the wild-type AR4, 
while the activity of M3 showed the most dramatic reduction to about $40 \%$ of wild-type activity. Western blot analysis using an anti-LexA antibody revealed negligible amounts of M3 (signal visible on the original film) but levels of M1, M2 and M4 were comparable with wild type (Fig. 3B). These results supported the view that conserved hydrophobic residues are important for AR-dependent transactivation.

\section{Conserved hydrophobic residues and AR4 conformation}

In addition to playing a direct role in constituting protein-protein interaction surfaces, hydrophobic residues are also likely to have an architectural role and to be involved in protein folding and structure. Recently, spectroscopy and partial proteolysis analysis of AR4 indicated that this polypeptide was structurally flexible but could adopt a more stable conformation in the presence of structurestabilising solutes or, significantly, the target protein RAP74 (Reid et al. 2002a).

In order to investigate the properties of the mutant polypeptides in vitro, AR4-M1 to -M4 were expressed in E. coli and purified by metal chelation chromatography (Fig. 4A). In order to test if the mutation of hydrophobic residues altered the folding of the AR4 polypeptide, the conformation surrounding two tryptophan residues at positions 396 and 432 was determined by measuring the steady-state fluorescence emission after excitation at $278 \mathrm{~nm}$. Excitation at $278 \mathrm{~nm}$ results in fluorescence emission from both tryptophan and tyrosine residues; in addition there can be energy transfer from tyrosine to tryptophan that is distance dependent. The spectrum thus provides information about the local conformation surrounding these residues. The fluorescence emission spectra were essentially similar for the wild-type polypeptide and mutants M1, M3 and M4, with the $\lambda \max$ for tryptophan emission at $343 \mathrm{~nm}$ (see below and data not shown). In contrast, the spectrum for AR4-M2 showed small but significant deviations from that of the wild-type AR4: the $\lambda \max$ for tryptophan showed a very modest but reproducible 'red shift' to $346 \mathrm{~nm}$, suggesting that the tryptophans were more surface exposed and there was a clear increase in tyrosine emission at $306 \mathrm{~nm}$ (Fig. $4 \mathrm{~B})$. The latter indicated an increase in the distance between donating tyrosine residues and the
A.

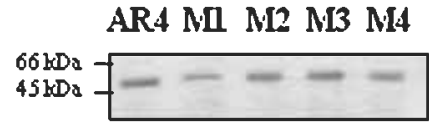

B.

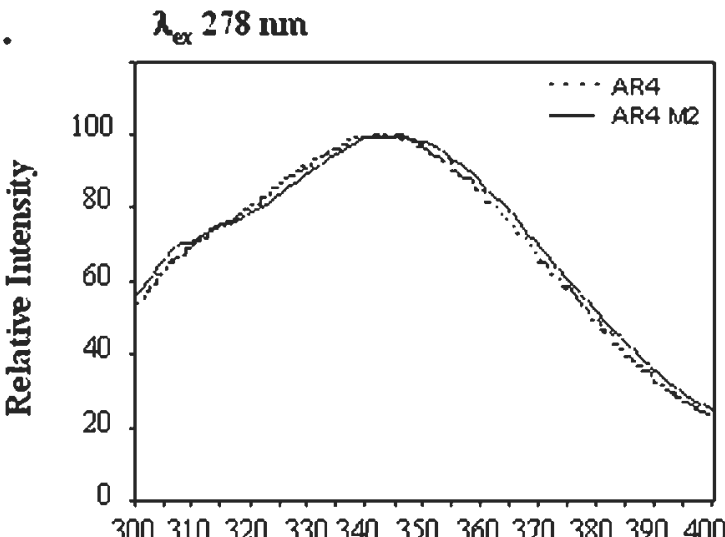

Wavelength (num)

Figure 4 Steady-state fluorescence emission spectrum for AR4-M2. (A) Recombinant AR4 and AR4-M1 to -M4 were expressed in E. coli and purified by metal chelation chromatography. Purified proteins were analysed by SDS-PAGE and Coomassie blue staining. (B) Fluorescence spectra for wild-type AR4 and AR4-M2 after excitation $\left(\lambda_{\text {ex }}\right)$ at $278 \mathrm{~nm}$. The dominant emission peak is from the tryptophan residues and the shoulder at $306 \mathrm{~nm}$ represent tyrosine emission. The spectra shown represent the average of three independent readings, corrected for buffer effects: the fluorescence intensity values for AR4 or AR4-M2 at the $\lambda$ max differed by less than $20 \%$ and the $\lambda \max$ by $1-2 \mathrm{~nm}$. The relative fluorescence intensity was calculated by setting the maximum fluorescence emission to $100 \%$ and is plotted against wavelength $(\mathrm{nm})$ corresponding to the maximum fluorescence emission.

accepting tryptophans and, taken together, both changes in the spectrum of AR4-M2 are consistent with a less ordered structure compared with the wild-type polypeptide. To investigate further the conformation of the wild-type and mutant polypeptides we used limited proteolysis. In agreement with the findings above, AR4-M2 was more susceptible to limited proteolysis with trypsin. Trypsin cleavage of AR4 resulted in three to four N-terminal fragments (Fig. 5 and Reid et al. 2002a). A similar 


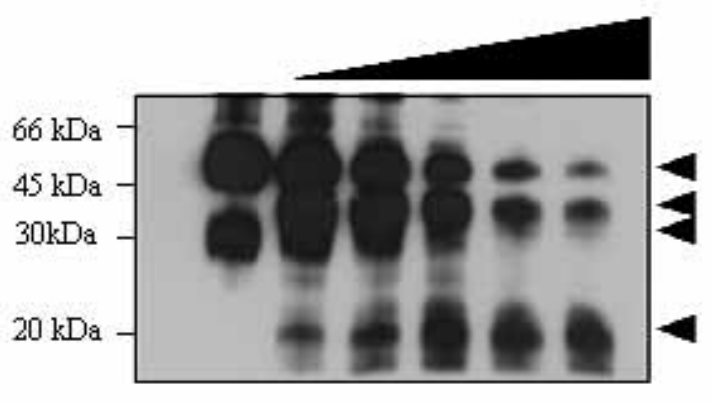

AR4wt

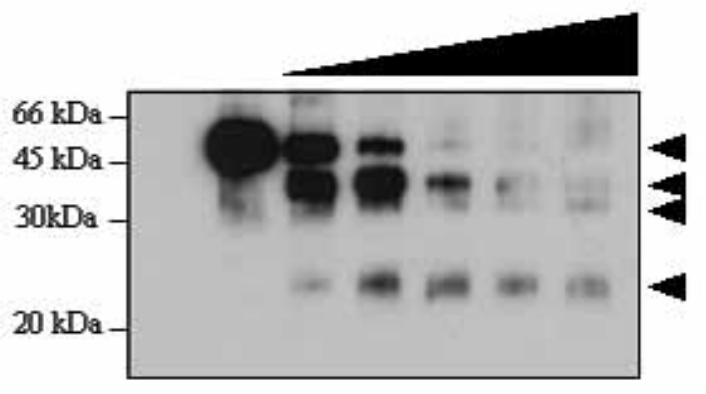

AR4M2

Figure 5 Partial proteolysis of AR4 wild type (wt) and mutant M2. Purified proteins were incubated with $0.25 \mathrm{ng} / \mu \mathrm{l}$ trypsin for $0,2,4,6,8$ or $10 \mathrm{~min}$ (indicated by solid triangles) and the resulting fragments resolved by SDS-PAGE. Full-length protein and $\mathrm{N}$-terminal fragments (arrowheads) were subsequently detected using an anti-histidine tag antibody (Sigma-Aldrich Co., Poole, Dorset, UK). Data are representative of at least three independent experiments.

pattern was observed for AR4-M2 except that the time required for cleavage of the full-length protein was much reduced, as was the resistance of the intermediate fragments (Fig. 5). Taken together, these results suggested that the mutations in M2 alter the conformation of the AR4 polypeptide and result in its being less structured and more susceptible to partial proteolysis with trypsin.

\section{Hydrophobic residues and protein-protein interactions}

In order to regulate gene expression, the AR must interact with the cell transcriptional machinery. We have previously identified and characterised an interaction between the AR4 polypeptide and the large subunit of the general transcription factor TFIIF (McEwan \& Gustafsson 1997, Reid et al. 2002b). Our group (Reid et al. 2002b) and others (Bevan et al. 1999, Ma et al. 1999, Callewaert et al. 2003) have also reported an interaction with the C-terminal domain of the pl60 family of coactivators and the AR-NTD. The binding of RAP74 to M1, M2 and M4 was essentially the same as for the wild-type polypeptide (Fig. 6A, left panel). In contrast, binding to M3 was significantly reduced (Fig. 6A, left panel). Although the above in vivo data suggested that M3 was less stable than wild-type AR4 this is unlikely to account for the decrease in RAP74 binding, as binding of M3 to SRC-CTD was equal to or slightly greater than the wild-type AR4 polypeptide (Fig. 6A, right panel).
Binding of SRG-CTD to M1, M2 and M3 was comparable with wild type, while M4 intriguingly showed a modest but reproducible enhancement of binding (Fig. 6A, right panel). In the context of this microtitre plate-binding assay, an excess of RAP74-CTD effectively competed for binding of radiolabelled SRG-CTD to AR4, while the non-binding protein GST did not (Fig. 6B). The binding data for AR4-M3 suggests a binding site for RAP74 involving methionine 244, leucine 246 and valine 248 and surrounding residues, and further demonstrated that the binding sites for TFIIF and the coactivator SRC-1 are likely to be distinct.

\section{Mapping the residues important for TFIIF binding}

TFIIF is a component of the general transcription machinery and consists of a tetramer of RAP30 and RAP74 subunits. We have previous characterised the interaction between AR4 and the holo-TFIIF and with the RAP74 subunit and identified serines 159 and 161 as being important for this interaction (Reid et al. 2002b; AR4-M6). We were therefore interested in comparing the conformational properties of M3 and M6. The steady-state fluorescence emission spectrum for AR4-M3 was essentially the same as for the wild-type polypeptide, with a $\lambda$ max for tryptophan emission at $343 \mathrm{~nm}$ (Fig. 7A). In contrast, the spectrum for M6 was significantly different with a 
A.

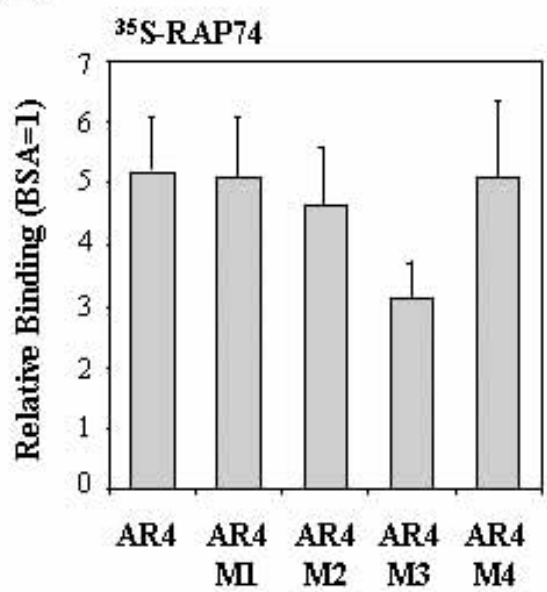

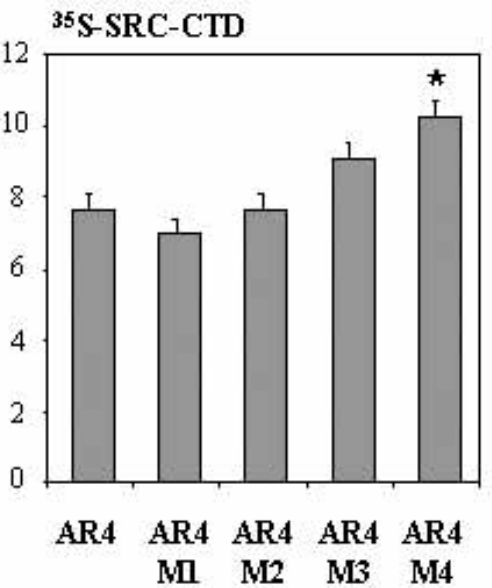

B.

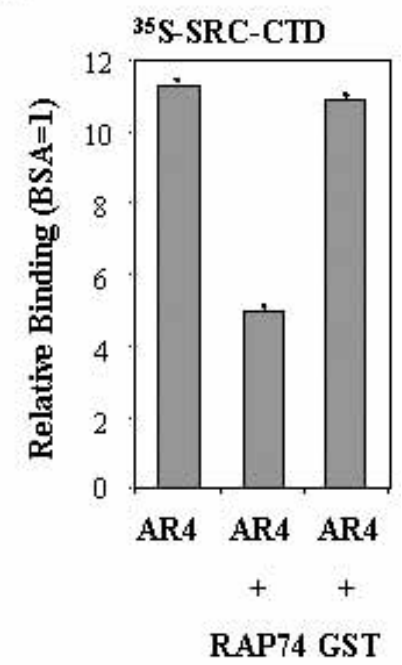

Figure 6 Protein-protein binding studies. (A) Radiolabelled RAP74 or SRC-CTD (amino acids 977-1441) were incubated with wild-type or mutant AR4 polypeptides and the binding relative to a BSA control was measured. Binding was carried out in triplicate and the results relative to the BSA control $(=1)$ plotted represent the means \pm S.D. The binding trends reported were seen in up to three separate experiments. The increased binding of AR4-M4 to SRC-CTD was statistically significant when compared with the wild-type AR4 using Student's $t$-test, with a $P$ value of almost $0.01\left(^{*}\right)$. (B) Representative data showing competition of SRC-CTD by RAP74-CTD (amino acids 363-517) but not by a non-specific competitor, GST. Binding was carried out in triplicate and the results relative to the BSA control $(=1)$ plotted represent the means \pm S.D.

'blue shift' in the $\lambda$ max for the tryptophans from $343 \mathrm{~nm}$ to $339 \mathrm{~nm}$ and the disappearance of the shoulder due to tyrosine emission (Fig. 7B). Both these changes were consistent with the AR4-M6 polypeptide being more structured. This was confirmed by limited proteolysis with trypsin, which showed that the M6 polypeptide was more resistant to digestion than either M3 (Fig. $7 \mathrm{C}$ and D) or the wild-type polypeptide (compare Figs 5 and 7). Taken together, these results suggested that certain mutating hydrophobic amino acids directly impair binding of TFIIF, while mutating serines 159 and 161 indirectly affect binding by altering the structural properties of the AR4 polypeptide.

\section{Discussion}

The main determinants for AR-dependent gene regulation have been mapped to the structurally distinct NTD. In an attempt to identify amino acids critical for transactivation activity we targeted hydrophobic amino acids within a highly conserved region for site-directed mutagenesis. Mutating pairs of residues (I229A/L236A; V240A/V242A;
L251A/L254A) reduced transactivation activity by 25-40\%. Mutating residues M244, L246 and V248 to alanines had a more dramatic affect on receptor activity, disrupting activity by at least $60 \%$. However, this mutant appeared to be less stable and/or poorly synthesised in vivo in yeast cells as little protein was detected. Although yeast cells lack members of the nuclear receptor superfamily, aspects of steroid receptor signalling can be reconstituted in vivo and in vitro by co-expression of the receptor and an appropriate reporter gene construct (see McEwan 2001 and references therein). Budding yeast has proved to be a useful model system for analysing receptor mutants, and mutational analysis of the AF-1 transactivation domain of the human and rat glucocorticoid receptors in yeast and mammalian cell gave comparable results (Almlölf et al. 1997, IniguezLluhi et al. 1997). Deletion analysis of the oestrogen receptor AF-1 domain in yeast and chicken embryo fibroblasts identified overlapping but not identical regions (Metzger et al. 1995). It is not clear if this reflected a limitation of the yeast assay or simply reflected the previously observed cell and promoter 


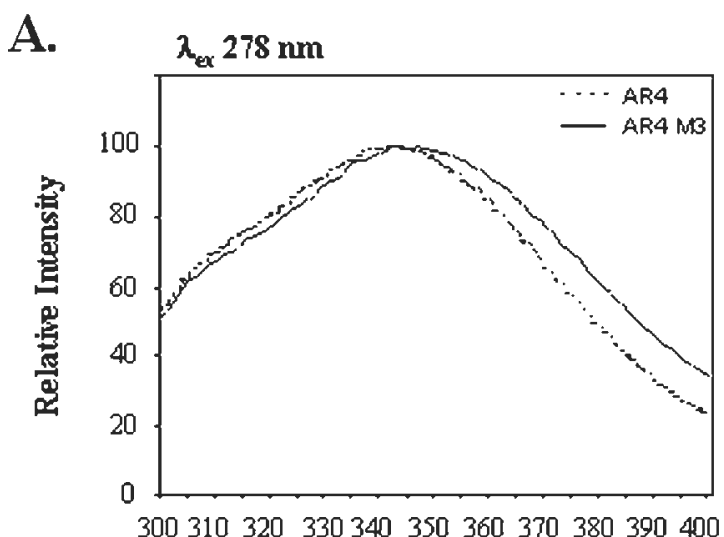

Wavelength (nm)

C.

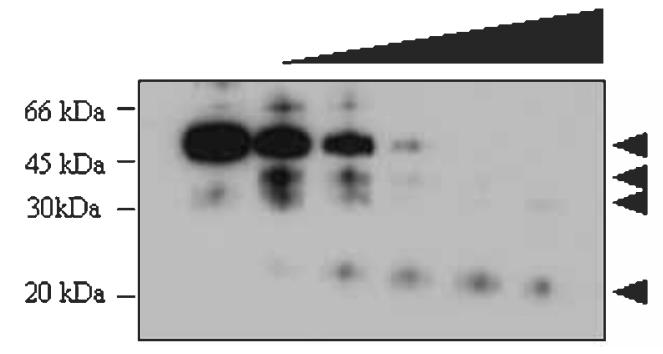

AR4M3
B.

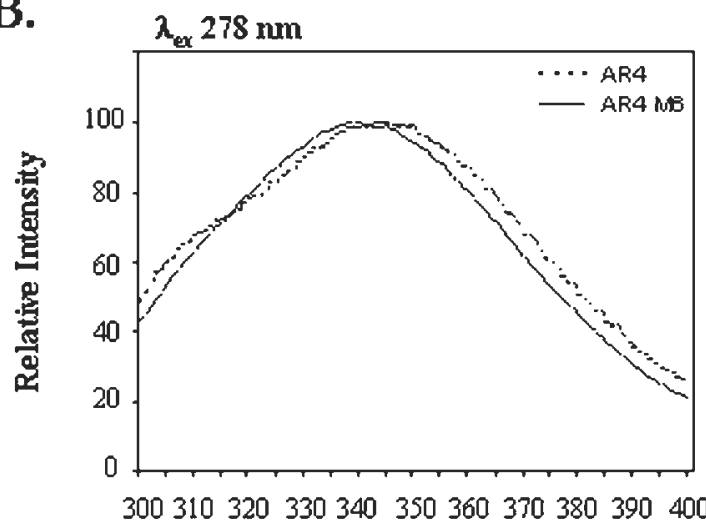

Wavelength (num)

D.

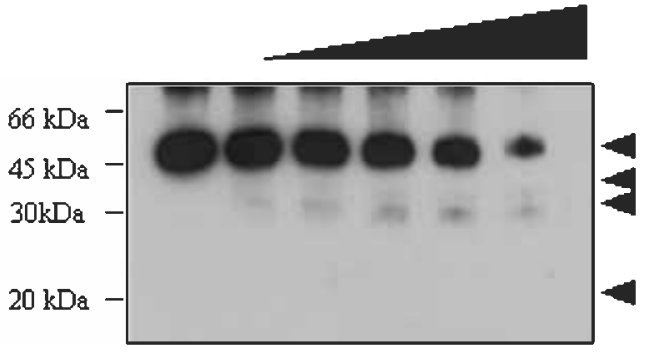

AR4M6

Figure 7 Steady-state fluorescence emission spectrum for AR4-M3 and -M6. (A) and (B) Fluorescence spectra for wild-type AR4 and AR4-M3 or -M6 respectively, after excitation at $278 \mathrm{~nm}$. The dominant emission peak is from the tryptophan residues $(\lambda \max =343-344 \mathrm{~nm}$ for wild type or M3) and the shoulder at $306 \mathrm{~nm}$ represents tyrosine emission. The emission spectrum for AR4-M6 showed a blue shift with the $\lambda$ max for tryptophan $=339 \mathrm{~nm}$. The spectra represent the average of three independent readings, corrected for buffer effects: the fluorescence intensity values for AR4-M3 and -M6 at the $\lambda$ max differed by $22 \%$ and $16 \%$ and the $\lambda \max$ by less than $3 \mathrm{~nm}$ or $1 \mathrm{~nm}$ respectively. The relative fluorescence intensity was calculated by setting tryptophan $\lambda \max$ to $100 \%$ and is plotted against wavelength. (C) and (D) Partial proteolysis of mutant polypeptides AR4-M3 and -M6 respectively. See legend to Fig. 5 for details.

specificities of the AF-1 domain (Metzger et al. 1995 and references therein). Recently, Sheppard et al. (2003) have reported similar affects for mutations that disrupt the ligand-dependent transactivation function (AF-2) of the oestrogen receptor when analysed in yeast. However, they also noted that other mutations within AF-2 that resulted in strong constitutive activity in mammalian cells had a more modest effect in yeast (Sheppard et al. 2003). Such differences may reflect the ability of the different transactivation domains of steroid receptors to contact the transcriptional machinery in yeast. Comparable results have been observed for the isolated AR AF-1 domain studied in yeast (Reid et al. 2002b, present study) and HeLa cells (Jenster et al. 1995) and with a double-point mutation introduced into the full-length $\mathrm{AR}$ analysed in COS cells (Chamberlain et al. 1996). However, it will be important to further investigate selected AR mutations described in the present study in a mammalian cell background and in the context of the full-length receptor.

Taken together, the data from fluorescence spectroscopy and limited proteolysis provided evidence for disruption of secondary and/or tertiary structure elements within AR4-M2. The 
steady-state fluorescence spectrum for M2 suggested a less ordered structure with a modest 'red shift' for the tryptophan $\lambda$ max from 343 to $346 \mathrm{~nm}$, indicative of the tryptophans being more fully exposed to solvent. In addition, a clear peak of tyrosine fluorescence at $306 \mathrm{~nm}$ was now seen, indicating a reduction in energy transfer and an increased separation between tyrosine and tryptophan residues. The sensitivity of this mutant to partial proteolysis with trypsin was also consistent with the structure being less ordered. Thus, the decrease in activity of AR4-M2 (V240/V242) may result from impaired folding of the mutant polypeptide. The fluorescence spectra for M1, M3 and M4 were similar to the wild-type AR4 polypetide with a tryptophan $\lambda \max$ of $343 \mathrm{~nm}$.

Mutant M3 was of particular interest as the recombinant protein expressed in $E$. coli and subsequently purified showed no obvious defects in synthesis or stability in contrast to expression in yeast cells. The reason for this difference is not clear but seems unlikely to be due to the presence or the absence of the LexA DBD per se, as an AR4-LexA fusion protein has been expressed and purified from E. coli at similar levels to the isolated AR4 (see McEwan \& Gustafsson 1997). The fluorescence emission spectra for wild-type AR4 and AR4-Lex were comparable, with $\lambda \max$ of $343 \mathrm{~nm}$ and $341 \mathrm{~nm}$ respectively, and although there were possible differences in the tyrosine emission there were no obvious gross conformational changes for the fusion protein (data not shown). The results of conformational analysis of AR4-M3 were similar to those of the wild-type protein. However, protein-protein binding studies with this polypeptide suggested that residues 244 , 246 and 248 are involved in binding RAP74, the large subunit of TFIIF. Our group has previously shown that mutations of the serines 159 and 161, within the sequence PSTLSL, selectively disrupt binding of RAP74 (AR4-M6; Reid et al. 2002b). Interestingly, AR4-M3 and -M6 do not share the same conformational properties. In contrast to both the wild-type and M3 polypeptides, AR4-M6 showed a more structured conformation, with the tryptophan residues being less surface exposed and an overall increase in protease resistance. We have concluded from these studies that the hydrophobic residues mutated in AR4-M3 (M244, L246 and V248) may form part of the binding surface for TFIIF, while the residues mutated in M6 have an indirect effect on binding by altering the structural flexibility of this domain. In light of these findings, it is of interest that Kumar et al. (2001) recently reported that the folding of the GR AF-1 $(\tau 1)$ domain significantly enhanced protein-protein interactions with the general transcription factor the TATA-binding protein (TBP) and the coactivators cAMP response element-binding protein (CREB)-binding protein (CBP) and SRC-1. We have preliminary data to suggest that induced folding of the AR-transactivation domain influences subsequent protein-protein interactions (authors' unpublished observations). Thus the picture that is emerging is one of a complex interplay between protein conformation and protein-protein interactions (see Kumar \& Thompson 2003).

In contrast to the $\mathrm{LBD}$ or $\mathrm{DBD}$, relatively few point mutations have been described within the AR-NTD (see Gottlieb et al. 1999; http:// www.mcgill.ca/androgendb). However, at least 16 single-point mutations have been reported from patients with mild to complete androgen insensitivity syndrome or prostate cancer, 10 of which fall within the region delineated by AR4. None of the mutations described are within the highly conserved region studied in the present paper, but reporter gene activity is available for two of the mutations, G214R and N222K (residues 213 and 221 relative to $\mathrm{AR} 4$ numbering), which exhibited $80 \%$ and $46 \%$ transactivation activity respectively (Wang et al. 1998, Lundberg-Giwercman et al. 2001). The mutated residues were located immediately $\mathrm{N}$-terminally of the highly conserved region and the glycine is conserved in different primates, rodents and Xenopus. In contrast, the asparagine only appears to be present in some primate species. Both these mutations were associated with individuals having mild androgen insensitivity syndrome. This suggests that mutations that directly modulate the transactivation activity of the receptor can lead to disruption of $\mathrm{AR}$ signalling in target tissues. It will therefore be of interest to determine what effect these two mutations have on interactions between the receptor and general transcription factors and coactivator proteins.

The importance of hydrophobic amino acids has been highlighted for a number of other cellular and viral activator proteins, together with the distribution of charged residues (particularly aspartic and glutamic acid). A comparison of the sequence 


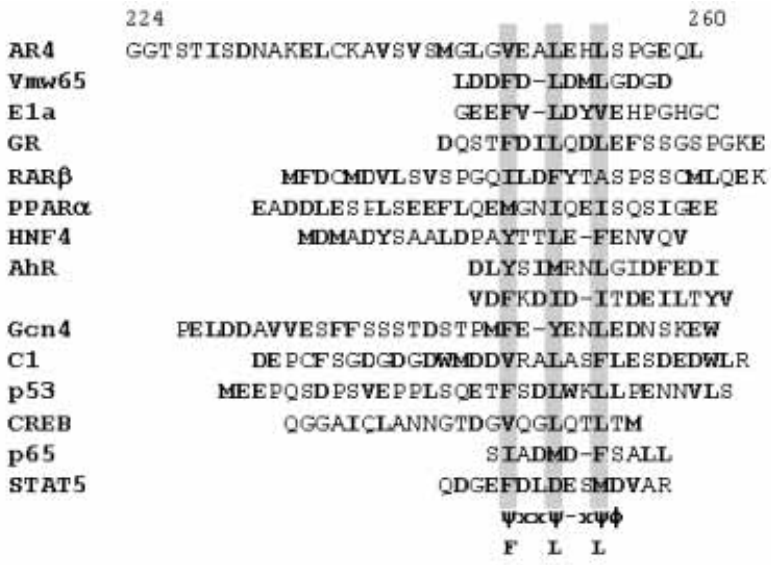

Figure 8 A hydrophobic amino acid signature motif seen in the AR and other cellular and viral activator proteins. Alignment of the sequences of cellular and viral transactivation domains highlighting the occurrence of a signature motif: $\psi / F x x \psi / L-X \psi \varphi$, where $\psi$ represents hydrophobic residues, - represents acidic amino acids and $\varphi$ represents hydrophilic residues. $F$, phenylalanine; $\mathrm{L}$, leucine; $\mathrm{x}$, any amino acid.

of the AR with that of a number of transactivation domains where mutational information is available reveals a good alignment of hydrophobic residues within the highly conserved sequence of $\mathrm{AF}-1$ and suggests a signature motif: $\psi / \mathrm{Fxx} \psi / \mathrm{L}-\mathrm{x} \psi \varphi$, where $\psi$ represents hydrophobic residues,-acidic residues and $\varphi$ represents hydrophilic residues (Fig. 8). Similar motifs have previously been suggested for the activators VP16, E1a, p65 (Rel A), RAR $\alpha$ and $\beta$, GR, Gal4, Gen4, Sp1, HNF-4 and p53 (see Cress \& Trizenberg 1991, Folkers et al. 1995, Green et al. 1998).

It has been proposed that long-range electrostatic interactions may be responsible for establishing initial binding between activators and target proteins and thus allowing for subsequent folding and formation of hydrophobic contacts at the binding interface (Uesugi et al. 1997). This model is supported by recent kinetic analysis of the binding between the $\mathrm{c}-\mathrm{Myc}$ transactivation domain and TBP, which appears to involve an initial fast step followed by a slower step that would be consistent with protein folding (Hermann et al. 2001). Where reported, activator-target protein interactions have generally been found to be of low affinity, with dissociation constants in the $\mu \mathrm{M}$ range $(\mathrm{Wu}$ et al. 1996, Chang et al. 1999, Parker et al. 1999, Melcher 2000, Hermann et al. 2001, Wärnmark et al. 2001).
Two notable exceptions are the interactions of the activation domains of CREB and hypoxiainducible factor- $1 \alpha$ (HIF-1 $\alpha$ ) with different domains of GBP, which have been reported to have dissociation constants in the $\mathrm{nM}$ range (Parker et al. 1999, Dames et al. 2003). Ionic interactions, hydrogen bonding and hydrophobic contacts all play a role in the formation and stabilisation of these complexes. It is interesting that the analysis of the structures of different transient protein-protein complexes reveals that the interfaces show a high degree of polarity (see Chang et al. 1999). The main difference between so-called low-affinity complexes $\left(\mathrm{K}_{\mathrm{D}}\right.$ in the $\mu \mathrm{M}$ range) and higher affinity complexes $\left(\mathrm{K}_{\mathrm{D}}\right.$ in the $\mathrm{nM}$ range) was the size of the interacting surface, with the later interactions having larger contact areas (Nooren \& Thornton 2003). It seems likely therefore that the distribution of charged and hydrophobic amino acids within the AR AF-1 domain will be functionally significant with respect to formation of protein-protein interfaces. However, the role of charged amino acids within the AR transactivation domain remains to be determined.

In the present study, we have highlighted the importance of conserved bulky hydrophobic residues for receptor-dependent transactivation and interactions with the basal transcription factor TFIIF. Mutating combinations of these residues lead to disruption of receptor-dependent activation and, in the case of M244, L246 and V248, to a significant reduction in specific protein-protein interactions.

\section{Acknowledgements}

We gratefully acknowledge support from the Association for International Cancer Research, Grant 99-094. We also thank Z Burton (Michigan State University, MI, USA), B W O’Malley (Baylor College of Medicine, TX, USA) and A P H Wright (Södertörns Högskolan University College, Huddinge, Sweden) for plasmid reagents.

\section{References}

Almlölf T, Wright APH \& Gustafsson J-A 1995 Role of acidic and phosphorylated residues in gene activation by the glucocortcioid receptor. Fournal of Biological Chemistry 270 17535-17540. 
Almlölf T, Gustafsson J-Å \& Wright APH 1997 Role of hydrophobic amino acid clusters in the transactivation activity of the human glucocorticoid receptor. Molecular and Cellular Biology $17934-945$.

Baskakov IV, Kumar R, Srinivasan GJYS \& Bolen DW \& Thompson EB 1999 Trimethylamine N-oxide-induced cooperative folding of an intrinsically unfolded transcription-activating fragment of human glucocorticoid receptor. Fournal of Biological Chemistry 274 10693-10696.

Beitel LK, Elhaji YA, Lumbroso R, Wing SS, Panet-Raymond V, Gottlieb B, Pinsky L \& Trifiro MA 2002 Cloning and characterisation of an androgen receptor N-terminal-interacting protein with ubiquitin-protein ligase activity. Fournal of Molecular Endocrinology 29 41-60.

Bevan CL, Hoare S, Claessens F, Heery DM \& Parker MG 1999 The AF1 and AF2 domains of the androgen receptor interact with distinct regions of SRC1. Molecular and Cellular Biology 19 8383-8392.

Blair WS, Bogerd HP, Madore SJ \& Cullen BR 1994 Mutational analysis of the transcription activation domain of Rel A: identification of a highly synergistic minimal acidic activation domain. Molecular and Cellular Biology 14 7226-7234.

Callewaert L, Verrijdt G, Christianens V, Haelens A \& Claessens F 2003 Dual function of an amino-terminal amphipatic helix in androgen receptor-mediated transactivation through specific and non-specific elements. Fournal of Biological Chemistry 278 8212-8218.

Callus BA \& Mathey-Prevot B 2000 Hydrophobic residues Phe751 and Leu753 are essential for STAT5 transcriptional activity. Journal of Biological Chemistry 275 16954-16962.

Chamberlain NL, Whitacre DC \& Miesfeld RL 1996 Delineation of two distinct type 1 activation functions in the androgen receptor amino-terminal domain. Fournal of Biological Chemistry 271 26772-26778.

Chang J-F, Phillips K, Lundback T, Gstaiger M, Landbury JE \& Luisi B 1999 Oct-1 POU and octomer DNA co-operate to recognise the Bob-1 transcription co-activator via induced folding. Fournal of Molecular Biology 288 941-952.

Combet C, Blanchet C, Geourjon C \& Deleage G 2000 NPS@: network protein sequence analysis. Trends in Biochemical Sciences 25 $147-150$.

Cress WD \& Trizenberg SJ 1991 Critical structural elements of the VP16 transcriptional activation domain. Science 251 87-90.

Dahlman-Wright K, Baumann H, McEwan IJ, Almlöf T, Wright AP, Gustafsson J-Å \& Härd T 1995 Structural characterization of a minimal functional transactivation domain from the human glucocorticoid receptor. PNAS 92 1699-1703.

Dames SJ, Martinez-Yamout M, Guzman RN, Dyson HJ \& Wright PE 2003 Structural basis for HIF-1 $\alpha /$ CBP recognition in the cellular hypoxic response. PNAS 99 5271-5276.

Donaldson L \& Capone JP 1992 Purification and characterization of the carboxyl-terminal transactivation domain of Vmw65 from herpes simplex virus type 1. Fournal of Biological Chemistry 267 1411-1414.

Dotzlaw H, Moehren U, Mink S, Cato ACB, Iniguez-Lluhi JA \& Baniahmad A 2002 The amino terminus of the human AR is target for corepressor action and antihormone agonism. Molecular Endocrinology 16 661-673.

Drysdale CM, Duenas E, Jackson BM, Reusser U, Braus GH \& Hinnebusch AG 1995 The transcriptional activator GCN4 contains multiple activation domains that are critically dependent on hydrophobic amino acids. Molecular and Cellular Biology 15 1220-1233.

Folkers GE, van Heerde EC \& van der Saag PT 1995 Activation function 1 of retinoic acid receptor $\beta 2$ is an acidic activator resembling VP16. Fournal of Biological Chemistry 270 23552-23559.

Freedman SJ, Sun Z-YJ, Poy F, Kung AL, Livingston DM, Wagner G \& Eck MJ 2002 Structural basis for the recruitment of CBP/p300 by hypoxia-inducible factor-1 $\alpha$. PNAS 99 5367-5372.
Gelman EP 2002 Molecular biology of the androgen receptor. Fournal of Clinical Oncology 20 3001-3015.

Gietz RD \& Woods RA 1994 High efficiency transformation with lithium acetate. In Molecular Genetics of Yeast, a Practical Approach, pp121-135. Ed. JR Johnston. Oxford: IRL Press.

Gottlieb B, Vasiliou DM, Lumbroso R, Beitel LK, Pinsky L \& Trifiro MA 1999 Analysis of exon 1 mutations in the androgen receptor gene. Human Mutation 14 527-539.

Green VJ, Kokkotou E \& Ladias JAA 1998 Critical structural elements and multi-target protein interactions of the transcriptional activator AF-1 of hepatocyte nuclear factor 4. fournal of Biological Chemistry 273 29950-29957.

Hayes SA, Zarnegar M, Sharma M, Yang F, Peehl DM, ten Dijke P \& Sun Z 2001 SMAD3 represses androgen receptor-mediated transcription. Cancer Research 61 2112-2118.

He B \& Wilson EM 2002 The $\mathrm{NH}_{2}$-terminal and carboxyl-terminal interactions in the human androgen receptor. Molecular Genetics and Metabolism 75 293-298.

Hermann S, Berndt KD \& Wright APH 2001 How transcriptional activators bind target proteins. Fournal of Biological Chemistry 276 40127-40132.

Hi R, Osada S, Yumoto N \& Osumi T 1999 Characterization of the amino-terminal activation domain of peroxisome proliferatoractivated receptor alpha. Importance of alpha-helical structure in the transactivating function. Fournal of Biological Chemistry 274 35152-35158.

Hope IA, Mahadevan S \& Struhl K 1988 Structural and functional characterisation of the short acidic transcriptional activator region of yeast GCN4 protein. Nature 333 635-640.

Hua Q X, Jia WH, Bullock BP, Habener JF \& Weiss MA 1998 Transcriptional activator-coactivator recognition: nascent folding of a kinase-inducible transactivation domain predicts its structure on coactivator binding. Biochemistry 37 5858-5866.

Iniguez-Lluhi JA, Lou DY \& Yamamoto KR 1997 Three amino acid substitutions selectively disrupt the activation but not the repression function of the glucocorticoid receptor $\mathrm{N}$-terminus. Fournal of Biological Chemistry $2724149-4156$.

Jackson BE, Drysdale CM, Natarajan K \& Hinnebusch AG 1996 Identification of seven hydrophobic clusters in GCN4 making redundant contributions to transcriptional activation. Molecular and Cellular Biology 16 5557-5571.

Jenster G, van der Korput HA, van Vroonhoven C, van der Kwast TH, Trapman J \& Brinkmann AO 1991 Domains of the human androgen receptor involved in steroid binding, transcriptional activation, and subcellular localization. Molecular Endocrinology $\mathbf{5}$ 1396-1404.

Jenster G, van der Korput HA, Trapman J \& Brinkmann AO 1995 Identification of two transcription activation units in the $\mathrm{N}$-terminal domain of the human androgen receptor. Fournal of Biological Chemistry 270 7341-7346.

Kang H-Y, Lin H-K, Hu Y-C, Yeh S, Huang K-E. \& Chang C 2001 From transforming growth factor-beta signaling to androgen action: identification of Smad3 as an androgen receptor coregulator in prostate cancer cells. PNAS 98 3018-3023.

Kumar R \& Thompson EB 2003 Transactivation functions of the N-terminal domains of nuclear hormone receptors: protein folding and coactivator binding. Molecular Endocrinology 17 $1-10$.

Kumar R, Lee C, Bolen DW \& Thompson EB 2001 The conformation of the glucocorticoid receptor $\mathrm{AFl} /$ taul domain induced by osmolyte binds co-regulatory proteins. Fournal of Biological Chemistry 276 18146-18152.

Lee H, Mok KH, Muhandiram R, Park K-H, Suk J-E, Kim D-H, Chang J, Sung YC, Choi KY \& Han K-H 2000 Local structural elements in the mostly unstructured transcriptional activation domain of human p53. Fournal of Biological Chemistry 275 29426-29432. 
Lin J, Chen J, Elenbass B \& Levine AJ 1994 Several hydrophobic amino acids in the p53 amino-terminal domain are required for transcriptional activation, binding to $\mathrm{mdm}-2$ and the adenovirus 5 E1B $55 \mathrm{kDa}$ protein. Genes and Development 8 1235-1246.

Lundberg-Giwercman Y, Nikoshkov A, Byström B, Pousette A, Arver S \& Wedell A 2001 A novel mutation (N233K) in the transactivating domain and the N756S mutation in the ligand binding domain of the androgen receptor gene are associated with male infertility. Clinical Endocrinology 54 827-834.

Ma H, Hong H, Huang SM, Irvine RA, Webb P, Kushner PJ, Coetzee GA \& Stallcup MR 1999 Multiple signal input and output domains of the 160-kilodalton nuclear receptor coactivator proteins. Molecular and Cellular Biology $196164-6173$.

McEwan IJ 2001 Bakers yeast rises to the challenge: reconstitution of mammalian steroid receptor signalling in S. cerevisiae. Trends in Genetics 17 239-243.

McEwan IJ \& Gustafsson J-A 1997 Interaction of the human androgen receptor transactivation function with the general transcription factor TFIIF. PNAS 94 8485-8490.

McEwan I J, Dahlman-Wright K, Ford J \& Wright AP 1996 Functional interaction of the c-Myc transactivation domain with the TATA binding protein: evidence for an induced fit model of transactivation domain folding. Biochemistry 35 9584-9593.

Markus SM, Taneja SS, Logan SK, Li W, Ha S, Hittelman AB, Rogatsky I \& Garabedian MJ 2002 Identification and characterization of ART-27, a novel coactivator for the androgen receptor N terminus. Molecular Biology of the Cell 13 670-682.

Melcher K 2000 The strength of acidic activation domains correlates with their affinity for transcriptional and non-transcriptional proteins. Fournal of Molecular Biology 301 1097-1112.

Metz R, Bannister AJ, Sutherland JA, Hagemeier C, O'Rourke EC, Cook A, Bravo R \& Kouzarides T 1994 c-Fos-induced activation of a TATA-box-containing promoter involves direct contact with TATA-box-binding protein. Molecular and Cellular Biology 14 6021-6029.

Metzger D, Ali S, Bornert J-M \& Chambon P 1995 Characterisation of the amino terminal transcriptional activation function of the human estrogen receptor in animal and yeast cells. Fournal of Biological Chemistry 270 9535-9542.

Nooren IMA \& Thornton JM 2003 Structural characterisation and functional significance of transient protein-protein interactions. Journal of Molecular Biology 325 991-1018.

O'Hare P \& Williams G 1992 Structural studies of the acidic transactivation domain of the Vmw65 protein of Herpes simplex virus using ${ }^{1} \mathrm{H}$ NMR. Biochemistry 31 4150-4156.

Parker D, Rivera M, Zor T, Henrion-Caude A, Radhakrishnan I, Kumar A, Shapiro LH, Wright PE, Montminy M \& Brindle PK 1999 Role of secondary structure in discriminating between constitutive and inducible activators. Molecular and Cellular Biology 19 5601-5607.

Radhakrishnan I, Perez-Alvarado GC, Parker D, Dyson HJ, Montminy MR \& Wright PE 1997 Solution structure of the KIK domain of CBP bound to the transactivation domain of GREB: a model for activator:coactivator interactions. Cell 91 741-752.

Regier JL, Shen F \& Trizenberg SJ 1993 Pattern of aromatic and hydrophobic amino acids critical for one of two subdomains of the VP16 transcriptional activator. PNAS $90883-887$.

Reid J, Kelly SM, Watt K, Price NC \& McEwan IJ $2002 a$ Conformational analysis of the androgen receptor amino-terminal domain involved in transactivation. Fournal of Biological Chemistry 277 20079-20086.

Reid J, Murray I, Watt K, Betney R \& McEwan IJ $2002 b$ The androgen receptor interacts with multiple regions of the large subunit of general transcription factor TFIIF. Fournal of Biological Chemistry 277 41247-41253.

Schmitz ML, dos Santos Silva MA, Altmann H, Czisch M, Holak TA \& Baeuerle PA 1994 Structural and functional analysis of the NF-кB p65 C-terminus. Fournal of Biological Chemistry 269 25613-25620.

Shen F, Triezenberg SJ, Hensley P, Porter D \& Knutson JR $1996 a$ Critical amino acids in the transcriptional activation domain of the Herpes virus protein VP16 are solvent exposed in highly mobile protein segments. Fournal of Biological Chemistry 271 4819-4826.

Shen F, Triezenberg SJ, Hensley P, Porter D \& Knutson JR 1996 b Transcriptional activation domain of the Herpes virus protein VP16 becomes conformationally constrained upon interaction with basal transcription factors. Fournal of Biological Chemistry 271 $4827-4837$.

Sheppard HM, Matsuda S, Harries JC, Kindle KB \& Heery DM 2003 Transcriptional activation by the estrogen receptor (Era) and steroid receptor coactivator (SRC-1) involves distinct mechanism in yeast and mammalian cells. Fournal of Molecular Endocrinology $\mathbf{3 0}$ $411-422$

Simental JA, Sar M, Lane MV, French FS \& Wilson EM 1991 Transcriptional activation and nuclear targeting signals of the human androgen receptor. Fournal of Biological Chemistry 266 510-518.

Tung L, Shen T, Abel MG, Powell RL, Takimoto GS, Sartorius CA \& Horwitz KB 2001 Mapping the unique activation function 3 in the progesterone B-receptor upstream segment. Fournal of Biological Chemistry 276 39843-39851.

Ueda T, Bruchovsky N \& Sadar MD 2002 Activation of the androgen receptor N-terminal domain by interleukin- 6 via MAPK and STAT3 signal transduction pathways. Fournal of Biological Chemistry 277 7076-7085.

Uesugi M, Nyanguile O, Lu H, Levine AJ \& Verdine GL 1997 Induced $\alpha$ helix in the VP16 activation domain upon binding to a human TAF. Science 277 1310-1313.

Walker S, Greaves R \& O'Hare P 1993 Transcriptional activation by the acidic domain of Vmw65 requires the integrity of the domain and involves additional determinants distinct from those necessary for TFIIB binding. Molecular and Cellular Biology 13 5233-5244.

Wang Q Ghadessy FJ \& Yong EL 1998 Analysis of the transactivation domain of the androgen receptor in patients with male infertility. Clinical Genetics 54 185-192.

Wärnmark A, Wikström A, Wright APH, Gustafsson J-Å \& Härd T 2001 The $\mathrm{N}$-terminal regions of estrogen receptor $\alpha$ and $\beta$ are unstructured in vitro and show different TBP binding properties. Fournal of Biological Chemistry 276 45939-45944.

Wright APH, Carlstedt-Duke J \& Gustafsson J-Å 1990 Ligand-specific transactivation of gene expression by a derivative of the human glucocorticoid receptor expressed in yeast. Fournal of Biological Chemistry 265 14763-14769.

Wu Y, Reece RJ \& Ptashne M 1996 Quantitation of putative activator-target affinities predicts transcriptional activating potentials. EMBO Journal 15 3951-3963.

Xing L \& Quinn PG 1994 Three distinct regions within the constitutive activation domain of cAMP regulatory elementbinding protein (CREB) are required for transcription activation. Fournal of Biological Chemistry $26928732-28736$.

Received 13 May 2003 Accepted 6 August 2003 